\title{
Adoption of Recommended Technologies by Sericulture Farmers in Krishnagiri District
}

\author{
B. Sivaranjani ${ }^{1 *}$ and K.A. Murugesh ${ }^{2}$ \\ ${ }^{1}$ Department of Sericulture, College of Agricultural Technology, Theni, India \\ ${ }^{2}$ Department of Sericulture, Forest College and Research Institute, Mettupalayam, Tamil \\ Nadu Agricultural University, Coimbatore, India \\ *Corresponding author
}

\begin{tabular}{|c|c|}
\hline \multicolumn{2}{|r|}{ A B S T R A C T } \\
\hline Keywords & \multirow{4}{*}{$\begin{array}{l}\text { The adoption of mulberry cultivation and silkworm rearing technologies by the sericulture } \\
\text { farmers was studied in Krishnagiri district. The data were collected from the selected } \\
\text { sample ninety sericulturists with a structured schedule by using personal interview } \\
\text { methods. Three categories of sericulturists viz. full adoption, partial and non-adoption } \\
\text { were made. Adoption on mulberry cultivation practices was high on mulberry variety } \\
(100 \%) \text {, seriboost/ poshan }(100 \%) \text {, spacing }(84.44 \%) \text { and chemical fertilizer }(78.88 \%) \text {. } \\
\text { In silkworm rearing technologies, adoption was high on shoot rearing }(100 \%) \text {, IPM for } \\
\text { uzifly }(100 \%) \text {, disinfection }(86.66 \%) \text {, hygienic maintenance }(88.88 \%) \text {, bed spacing } \\
\text { maintenance }(86.66 \%) \text {, separate rearing house }(82.22 \%) \text {, bed cleaning }(77.77 \%) \text {, } \\
\text { improved mountages }(76.66 \%) \text {, IPM for silkworm diseases (76.66\%) and room } \\
\text { disinfection }(74.44 \%) \text {. }\end{array}$} \\
\hline $\begin{array}{l}\text { Sericulture, } \\
\text { Adoption, } \\
\text { Mulberry, } \\
\text { Silkworm, } \\
\text { Recommended } \\
\text { technologies }\end{array}$ & \\
\hline Article Info & \\
\hline $\begin{array}{l}\text { Accepted: } \\
\text { 20 January } 2019 \\
\text { Available Online: } \\
\text { 10 February } 2019\end{array}$ & \\
\hline
\end{tabular}

\section{Introduction}

Sericulture is an expanding industry in India. Among the sericulture developing country India stands second in the production of silk next to China. Sericulture plays a major role in the upliftment of rural population both socially and economically (Sreenivasa and Hiriyanna, 2014). Improved rearing techniques have been popularized on a large scale during the past 30 years in South India. As a result, it has been possible for the sericulturists adopting the new technique to step up the average yield from the earlier level of $40 \mathrm{kgs}$ to $70 \mathrm{kgs} / 100 \mathrm{dfls}$ at present. Also, total loss of one crop out of every 4-5 crop experienced earlier has been considerably reduced. Although, to a large extent, the new techniques have been fairly understood and practiced by most of the sericulturists today, the need still exists to educate them further and also others who are yet to take it, so that the average crop yield could be further improved to the level of 80 $\mathrm{kgs} / \mathrm{dfls}$. 
Introduction of improved sericultural technologies will not only result in increasing the quality silk production in the country, but also helps in improving the quality and standard of living of rural population. It is a proven fact that adoption of recommended sericultural technologies gives good returns to the farmers.

\section{Materials and Methods}

The study was conducted in Krishnagiri, Hosur, Veppanapalli and Kaveripattinam blocks of Krishnagiri district.

\section{Measurement of dependent variables (adoption level)}

The data collection was done with the use of well constructed interview schedule. The level of adoption of sericulture farmers about sericulture technology was measured by computing adoption score. To find out the extent of adoption of the selected sericulture practices, adoption index was used. For each practice index was calculated as below.

Level of adoption of practice $=$

\section{Actual practice followed}

Recommended practice

X 100

For each of the recommended practices score of two was assigned for full adoption of practices. One score and zero score were assigned to partial adoption and non-adoption of practices, respectively. The data was presented in frequency and percentage.

\section{Results and Discussion}

\section{Extent of adoption of different sericulture practices}

The findings pertaining to the extent of adoption of recommended practices and differential adoption behaviour of farmers.

Extent of adoption of mulberry cultivation technologies

Adoption level of mulberry technologies tabulated and presented in Table 1. It indicates that the full adoption level was observed in mulberry variety $(100 \%)$, seriboost/poshan $(100 \%)$, spacing $(84.44 \%)$, chemical fertilizer $(78.88 \%)$, drip irrigation (77.77\%), farm yard manure $(65.55 \%)$, soil test and reclamation (62.22 \%), IPM for leaf roller $(53.33 \%)$, IDM for root $\operatorname{rot}(53.33 \%)$, green manuring (50 \%), IPM for Papaya mealy bug (48.88 \%) and biofertilizer (45.55 $\%)$. The reason for high level of adoption is sufficient knowledge about mulberry cultivation practices. Similar findings were observed by Meenal and Rajan (2006), Siddaramaiah and Prakash Kumar (1994).

Partial adoption was observed in green manure (42.22\%), IDM for root rot (41.11 $\%)$, IPM for leaf roller $(38.88 \%)$, IPM for Papaya mealy bug (38.88\%), farm yard manure (34.44 \%), soil testing and reclamation $(31.11 \%)$, chemical fertilizer $(21.11 \%)$ and biofertilizer (15.55\%). The lack of thorough knowledge and interest are the reason for partial adoption.

Non-adoption was observed in biofertilizer (38.88\%), drip irrigation (22.22\%), spacing (15.55\%), IPM for Papaya mealy bug (12.22 $\%)$, soil testing $(7.77 \%)$, green manure $(7.77$ $\%)$, IPM for leaf roller (7.77 \%) and IDM for root rot $(5.55 \%)$. This might be due to nonavailability and lack of knowledge on sericulture technologies. The finding is in line with the findings of Kumaresan et al., (2005).

\section{Extent of adoption of silkworm rearing} technologies

The silkworm rearing practices like shoot rearing and IPM for uzifly was found to be under high adoption level (100\%). Similar 
findings were observed with Sariful Islam (2004).

The maintenance of hygienic condition $(88.88$ $\%)$, bed disinfection $(86.66 \%)$, bed spacing maintenance (86.66 \%), separate rearing house $(82.22 \%)$, bed cleaning $(77.77 \%)$, improved mountages (76.66 \%), IPM for silkworm diseases (76.66 \%), room disinfection (74.44 \%), temperature and humidity maintenance $(64.44 \%)$, silkworm race $(56.66 \%)$, incubation of dfls $(22.22 \%)$ and black boxing $(22.22 \%)$ have been adopted fully (Table 2).

Table.1 Extent of adoption of mulberry cultivation technologies $(\mathrm{n}=90)$

\begin{tabular}{|c|l|c|c|c|c|c|c|}
\hline SI.No. & \multicolumn{1}{|c|}{ Technologies } & \multicolumn{2}{|c|}{ Full adoption } & \multicolumn{2}{c|}{ Partial adoption } & \multicolumn{2}{c|}{ Non-adoption } \\
\cline { 3 - 8 } & & Number & Percentage & Number & Percentage & Number & Percentage \\
\hline 1. & Soil test \& reclamation & 56 & 62.22 & 28 & 31.11 & 6 & 7.77 \\
\hline 2. & Mulberry variety: V1 & 90 & 100 & - & - & - & - \\
\hline 3. & Spacing: 90 X 90 & 76 & 83.33 & - & - & 14 & 15.55 \\
\hline 4. & Drip irrigation & 70 & 77.77 & - & - & 20 & 22.22 \\
\hline 5. & FYM application & 59 & 65.55 & 31 & 34.44 & - & - \\
\hline 6. & Green manuring & 45 & 50.00 & 3 & 42.22 & 7 & 7.77 \\
\hline 7. & Biofertilizer & 41 & 45.55 & 14 & 15.55 & 35 & 38.88 \\
\hline 8. & Chemical fertilizer & 71 & 78.88 & 19 & 21.11 & - & - \\
\hline 9. & Seriboost/ Boosan & 90 & 100 & - & - & - & - \\
\hline 10. & IPM for leaf roller & 48 & 53.33 & 35 & 38.88 & 7 & 7.77 \\
\hline 11. & IDM for root rot & 48 & 53.33 & 37 & 41.11 & 5 & 5.55 \\
\hline 12. & IPM for PMB & 44 & 48.88 & 35 & 38.88 & 9 & 12.22 \\
\hline
\end{tabular}

Table.2 Extent of adoption silkworm rearing technologies $(\mathrm{n}=90)$

\begin{tabular}{|c|c|c|c|c|c|c|c|}
\hline \multirow[t]{2}{*}{ SI.No. } & \multirow[t]{2}{*}{ Technologies } & \multicolumn{2}{|c|}{ Full adoption } & \multicolumn{2}{|c|}{ Partial adoption } & \multicolumn{2}{|c|}{ Non-adoption } \\
\hline & & Number & Percentage & Number & Percentage & Number & Percentage \\
\hline 1. & $\begin{array}{l}\text { Silkworm race: CSR } \\
\text { hybrid }\end{array}$ & 51 & 56.66 & - & - & 39 & 43.33 \\
\hline 2. & Separate rearing house & 74 & 82.22 & - & - & 16 & 17.77 \\
\hline 3. & Shoot rearing & 90 & 100 & - & - & - & - \\
\hline 4. & Room disinfection & 67 & 74.44 & 23 & 25.55 & - & - \\
\hline 5. & $\begin{array}{l}\text { Bed disinfection: } 4 \mathrm{~kg} / \\
100 \mathrm{dfls}\end{array}$ & 78 & 86.66 & 12 & 13.33 & - & - \\
\hline 6. & Hygiene maintenance & 80 & 88.88 & 20 & 22.22 & - & - \\
\hline 7. & Incubation of dfls & 20 & 22.22 & - & - & 70 & 77.77 \\
\hline 8. & Black boxing & 20 & 22.22 & - & - & 70 & 77.77 \\
\hline 9. & Bed spacing maintained & 78 & 86.66 & 12 & 13.33 & - & - \\
\hline 10. & Bed cleaning & 70 & 77.77 & 20 & 22.22 & - & - \\
\hline 11. & Temperature \& humidity & 58 & 64.44 & 32 & 35.55 & - & - \\
\hline 12. & Improved mountages & 69 & 76.66 & 21 & 23.33 & - & - \\
\hline 13. & IPM for Uzi fly & 90 & 100 & - & - & - & - \\
\hline 14. & $\begin{array}{l}\text { IDM for Silkworm } \\
\text { diseases }\end{array}$ & 69 & 76.66 & 12 & 13.33 & 9 & 10 \\
\hline
\end{tabular}


Partial adoption was observed in temperature and humidity maintenance $(35.55 \%)$, room disinfection $(25.55 \%)$, improved mountages $(23.33 \%)$, bed cleaning (22.22 \%), maintenance of hygienic condition $(22.22 \%)$, bed disinfection (13.33\%), bed spacing maintenance $(13.33 \%)$ and IPM for silkworm diseases $(13.33 \%)$. Lack of adequate knowledge on improved technology and interest are the reason for partial adoption. Non-adoption was seen in IPM for silkworm diseases $(76.66 \%)$, silkworm race $(43.33 \%)$, separate rearing house $(17.77 \%)$, incubation of dfls $(77.77 \%)$ and black boxing $(77.77 \%)$. This might be due to non-availability and lack of knowledge about these practices.

Separate rearing house and maintenance of temperature and relative humidity were associated with high cost. Poor economic condition did not permit the farmers to construct separate house for silkworm rearing. Lack of knowledge to adopt recommended silkworm race is the reason for non adoption. The above findings are in line with Singhivi et al. (1994), Qadri et al. (2010) and Sujatha et al. (2006).

\section{Summary}

Full adoption level was observed in mulberry variety $(100 \%)$, followed by seriboost/ poshan $(100 \%)$, spacing $(84.44 \%)$, chemical fertilizer (78.88 \%), drip irrigation $(77.77 \%)$, farm yard manure $(65.55 \%)$, soil test and reclamation (62.22\%), IPM for leaf roller $(53.33 \%)$, IDM for root rot $(53.33 \%)$, green manuring (50 \%), IPM for Papaya mealy bug $(48.88 \%)$ and biofertilizer $(45.55 \%)$. The silkworm rearing practices like shoot rearing, IPM for uzifly had reported higher adoption level $(100 \%)$. Maintenance of hygienic condition (88.88\%), bed disinfection (86.66 $\%$ ), bed spacing maintenance (86.66 \%), separate rearing house $(82.22 \%)$, bed cleaning $(77.77 \%)$, improved mountages
(76.66 \%), IPM for silkworm diseases (76.66 $\%$ ), room disinfection (74.44\%), temperature and humidity maintenance $(64.44 \%)$ and silkworm races $(56.66 \%)$ and have been adopted fully.

This study concludes, with respect to practice adoption of sericulture technologies, nonadoption was found against the practices viz., bio-fertilizer, silkworm races, egg incubation and black boxing. Hence, it is suggested to creating more awareness about the improved technologies among the sericulture farmers to produce the raw silk in to a desired level.

\section{References}

Kumaresan, P., Srinivasa, G. and Vijaya Prakash, N.B. 2005. Productivity and profitability in rainfed sericulture - A study in the district of Chamaraja nagar in Karnataka. Agricultural Economics Research Review, CSR\&TI, Mysore. 18: 91-102.

Meenal, R. and Rajan, R.K. 2006. Knowledge and adoption level of bivoltine sericulture technologies by farmers. Indian. J. Seric., 45 (2): 188-191.

Qadri, S.F.I., Malik, M.A., Sabhat, A. and Malik, F.A. 2010. Adoption of improved sericultural practices by sericulturists in border area of Kashmir. Int. J. Agricult. Stat. Sci., 6 (1): 197-201.

Sariful Islam. 2004. Adoption of technologies by sericulturists in Mandya and Tumkur districts of Karnataka - A post evaluation study. M.Sc. dissertation, Central Sericultural Research and Training Institute, Mysore. p. 58.

Siddaramaiah and Prakash Kumar. 1994 Adoption of improved sericultural practices by big and small farmers. Indian Silk, 33 (4): 5-7.

Singhvi, N.R., Rao, M.K.S., Rao, Y.R.M., Iyengar, M.N.S. and Datta, R.K. 
(1994). Knowledge level and adoption of new sericulture technology by farmers in Hunsur taluk, Mysore district, Karnataka State: An evaluation. Indian J. Seric., 33 (1): 48-55.

Sreenivasa, B.T. and Hiriyanna. 2014. A study on the factors influencing adoption of new technologies in nontraditional sericultural area of
Chitradurga district, Karanataka. Global journal of Biology, Agriculture \& Health Sciences, 3 (1): 239-243.

Sujatha, B., Reddy, P.L., Sankar Naik, S. and Sujathamma, P. 2006. A study on adoption of recommended mulberry cultivation practices by sericulturists in Chittoor district of Andhra Pradesh. Indian J. Seric., 45 (2): 142-148.

\section{How to cite this article:}

Sivaranjani, B., and Murugesh, K.A. 2019. Adoption of Recommended Technologies by Sericulture Farmers in Krishnagiri District. Int.J.Curr.Microbiol.App.Sci. 8(02): 2784-2788. doi: https://doi.org/10.20546/ijcmas.2019.802.326 